\title{
Politics a "Chilly" Environment for Undergraduate Women in Norway
}

Cissy J. Ballen, University of Minnesota

Dahsol Lee, University of Minnesota

Lise Rakner, University of Bergen

Sehoya Cotner, University of Minnesota and University of Bergen

ABSTRACT Gender differences in academic performance and attitudes are widespread in male-stereotyped disciplines but rarely are studied in the social sciences. To assess the extent that gender influences the behavior of undergraduate women in political science, participation was analyzed in a large $(\mathrm{N}=130)$ introductory comparative-politics class at the University of Bergen-a large public university in Norway. In the 2016 fall semester, observers documented classroom behaviors of men and women using a protocol that characterizes types of in-class participation. Findings showed that women participate less than expected given their observed numbers in the classroom. After the semester ended, we provided an opportunity for students to describe why they chose to participate and whether they felt that barriers existed in the classroom that prevented them from expressing their opinions. This article characterizes those responses and presents the first study to draw conclusions about the gendered educational experience in political science by integrating these qualitative and quantitative results.

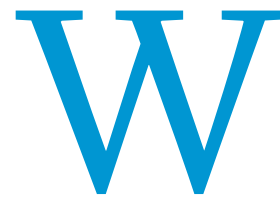

omen are underrepresented across political science disciplines (APSA 2005), which underscores the need for effective approaches that promote and retain women who pursue American politics, political theory, international relations, and comparative politics at the undergraduate level and throughout the "academic pathway." Women experience unique social challenges when entering university, including feelings of marginalization in male-dominated fields (Ceci, Williams, and Barnett 2009; Steele, James, and Barnett 2002); low self-efficacy (Betz and Hackett 1981); and discrimination in and out of the classroom (Banks 1988; Moss-Racusin et al. 2012). In the political sciences, previous work has demonstrated the susceptibility of women to "stereotype threat" in political knowledge (McGlone, Aronson, and Kobrynowicz 2006). Stereotype threat

Cissy J. Ballen is a postdoctoral associate in teaching and learning at the University of Minnesota and in the BioCEED Centre of Excellence in Biology Education at the University of Bergen, Norway. She can be reached at balleo27@umn.edu. Dahsol Lee is an undergraduate student at the University of Minnesota.

Lise Rakner is professor of comparative politics at the University of Bergen. Lise may be reached at Lise.Rakner@uib.no.

Sehoya Cotner is associate professor of teaching and learning at the University of Minnesota and in the BioCEED Centre of Excellence in Biology Education at the University of Bergen, Norway. Sehoya may be reached at sehoya@umn.edu. is defined as concern about confirming a negative stereotype about one's group, and it occurs in competitive and evaluative contexts such as a classroom or a testing environment (Steele 1997). For example, in one study, women performed better on a difficult math test when the examiner described the test as not producing gender differences. In this case, the stereotype threat was reduced by lowering the sense of risk for the student to be judged based on the stereotype that representatives of her gender (i.e., women) are poor at math (Spencer, Steele, and Quinn 1999). The outcome of repeated exposure to social challenges for women is their attrition at the postgraduate, postdoctoral, and faculty levels of academic rank (APSA 2005; Bates, Jenkins, and Pflaeger 2012; Monroe and Chiu 2010; Timperley 2013). Among faculty, Timperly (2013) identified several factors from the literature that serve as barriers that prevent women's progression in political science. Examples include a negative culture of research that discourages the examination of questions that fall outside of the more "traditional" scope of political science (e.g., gender and family) (Monroe et al. 2008); a "chilly" professional climate that devalues junior faculty who are women (Anonymous 1999); and a "double bind" that results from conflicts between gender stereotypes and professional expectations (Ong et al. 2011). Women in political science also engage in professional service more than their male peers (Mitchell and Hesli 2013), which may contribute 
to their lower publication rates across academic rank (Hesli and Lee 2011).

Although gender inequality in political science has been documented primarily at the faculty level, we expect that students' experiences as undergraduates influence these later outcomes. consequence may be that students-particularly women-feel less comfortable participating when instructors change every week. Therefore, in our analyses, we considered the effect of gender on student participation in guest-lecturer classes separately $(\mathrm{N}=$ five lectures and 55 observations) from our analysis of participation

\section{Examining college experiences may be particularly important because peer interactions and academic performance impact students while they navigate identities as competent political scientists.}

We also can take cues from research on undergraduates in maledominated STEM fields, where attrition of women is both progressive (i.e., their proportion declines in more advanced positions) and persistent (i.e., little progress has been made despite efforts), with numerous and complex underlying drivers (Blickenstaff 2005; Burke and Mattis 2007). Examining college experiences may be particularly important because peer interactions and academic performance impact students while they navigate identities as competent political scientists. To our knowledge, this article presents the first study that documents academic inequity during the course of a semester in an undergraduate political science classroom. It does so by first quantifying whole-class participation and then by presenting a qualitative investigation into the perspectives of women and men about the classroom environment.

\section{MATERIALS AND METHODS}

This study took place at the University of Bergen (UiB), a public university located in Bergen, Norway. Our study focused on one introductory comparative-politics course (i.e., SAMPOL 100) that is recommended to all comparative-politics majors and is attended primarily by students in their first semester at UiB. In the fall of 2016, SAMPOL 100 took place on campus in a traditional lecture hall (i.e., 130 students completed the course). ${ }^{1}$ The gender composition of the class was $48 \%$ women. In our analyses, we expected that $48 \%$ of student participants would be women unless something prevented that group from speaking, and we tested the actual observed percentage against this expected value.

\section{CLASSROOM OBSERVATIONS}

We used an observation protocol that characterized seven in-class interactions between students and the instructor during an approximate two-hour (i.e., two 45-minute) class period (Eddy, Brownell, and Wenderoth 2014). For each type of interaction, observers noted the gender of students who participated. If the gender identity of a student was unclear, observers asked the instructor for clarification. In our dataset, students interacted with instructors using two of the seven different types of common interaction classifications (see Ballen et al. 2017, appendix 1): (1) asking a spontaneous question or making a comment, and (2) volunteering an answer following an instructor-generated question. The course is designed as an introduction to the subject and the department: the lead instructor gives five lectures at the beginning of the course, followed by 10 individual lectures from various faculty members (presenting area cases). The intended benefit of the course structure is to give students exposure to the faculty and expertise during their first semester. One unintended during the lead instructor's lectures $(\mathrm{N}=$ three lectures and 77 observations). We only included instructors who had a total of five or more student interactions in any of the pooled categories. This led to the exclusion of two guest lecturers who were both men. The included guest lecturers were two women and three men, and the lead instructor was a woman.

\section{QUALITATIVE DATA ANALYSIS}

When the semester ended, the lead instructor revealed to students that in-class observers quantified whole-class participation to examine gendered behaviors. After sharing the observation data, the instructor invited students to take an online survey designed to elicit their responses to the data. Survey participation was anonymous and voluntary, and the participant's gender was the only personal information collected. Specifically, students were asked to describe their views "as to why there is such a huge difference between participation of women and men in class." Students could answer this broad question as they saw fit by focusing on one of the following questions: (1) What could explain this?; (2) What made you participate during lectures?; or (3) What prevented you from participating? Of the approximate 90 students who regularly attended the lectures, 17 (19\%) participated in the survey. After reviewing student responses, the research team coded the responses according to three broad themes, as listed in table 1.

\section{STATISTICAL ANALYSES}

We ran analyses separately for each type of student-instructor interaction (i.e., spontaneous question or comment and volunteer response) as well as all combined interactions for guest lecturers' classes and the lead lecturer's classes. To assess whether there were gendered patterns in response to each interaction type, we used a one-sample $t$-test to examine whether the proportion of interactions involving women in a class is more or less than expected (given the number of women in the class) in each type of interaction individually and then all interactions combined.

\section{RESULTS}

In the 2016 fall semester, we observed 55 interactions among guest lecturers during five class periods; in the lead instructor's classes, we observed 77 interactions during three class periods.

Among the guest lecturers, we found significant differences between the number of women enrolled in the class (48\%) and the number of questions asked or spontaneous comments made (i.e., without being prompted by the instructor) by women (i.e., 2 of $18 ; t(17)=5.36$; two-tailed $p<0.0001$ ). The number of 
volunteer responses attributed to women (i.e., 5 of 37) was significantly lower (i.e., $t(36)=6.76 ; p<0.0001$ ) than expected based on the number of women in the classroom. In other words, after an instructor posed a question to students, a woman was less likely than a man to raise her hand. Combined, the total number of women who spoke in the classroom during the observed class periods was significantly lower than expected based on we categorized 15 responses (88\%) in one of the three pooled themes, as outlined in table 1.

\section{DISCUSSION}

Although Norway is lauded as one of the most politically equitable countries in the world (Bekhouche et al. 2013), undergraduate women in an introductory comparative-politics course spoke up

\section{The number of volunteer responses attributed to women (i.e., 5 of 37) was significantly lower (i.e., $t(36)=6.76 ; p<0.0001$ ) than expected based on the number of women in the classroom. In other words, after an instructor posed a question to students, a woman was less likely than a man to raise her hand.}

the women who were in the classroom (i.e., seven of $55 ; t(54)=$ 8.66; $p<0.0001$ ) (figure 1). In the lead instructor's lectures, we also found a significant difference between the number of women enrolled in the class $(48 \%)$ and the number of spontaneous questions asked or comments made by women (o of 13; $p<0.0001)$ or the number of volunteer responses attributed to women (i.e., 11 of $64 ; t(63)=7.32$; two-tailed $p<0.0001$ ). When we combined these values, the total number of women who spoke during the lead instructor's classes was significantly less than expected (i.e., 11 of $77 ; t(76)=9.40$; two-tailed $p<0.0001$ ) (see figure 1).

Our second objective, accomplished through interviews with students, was to qualitatively explore barriers in the classroom that may prevent women from participating $(\mathrm{N}=17)$ (see table 1 ). The participants reported many reasons why women do not participate in class; however, three recurring themes that were identified from the interviews became apparent: (1) women are scared of being wrong, (2) people who speak are more prepared, and (3) men more naturally speak. Of the 17 student responses, significantly less than men across all measures of participation-a result more dramatic than previously observed in some STEM courses (Ballen et al. 2017; Eddy, Brownell, and Wenderoth 2014). Students reported that the reluctance of women to participate may be due to fear of being wrong; because those who speak in class-woman or man-are more prepared and knowledgeable about the subject; or because men more naturally speak up in groups.

Although our results revealed a strong pattern, we recognized that a limitation of this study is that the data presented was from only one classroom and one semester. Furthermore, the origin of the observed gap in participation remains unclear, as well as the extent of the gender gap in student performance and attrition in political science. Although students suggested that those who speak in class are more prepared or have more knowledge, we are not aware of research that supports those claims. This would require either measures of preparation, or how much students study the material before the lecture, or a gauge of student knowledge through validated knowledge-assessment inventories.

Table

Students' Views on Why Women Participated Less in the Classroom ( $=17)$

Pooled-Response Category

Women are scared of being wrong $(\mathrm{N}=7)$ People who speak
prepared $(\mathrm{N}=5)$ up $(\mathrm{N}=3)$

\section{Student Comments}

“I think girls are more insecure and scared they're wasting other people's time." (Woman respondent)

"I don't raise my hand because I have to think through my answer [and by the time I form a response it is] too late to answer. This is because I am scared of answering the question wrong and have to think it through until I am absolutely sure. I think this is typical for a lot of female students." (Woman respondent)

“...it seems like girls are more scared of getting the answer wrong and thus choose to not answer at all, as they might be wrong. Furthermore, I'm not scared of talking in front of bigger groups, and if I get something wrong I don't really feel like other students are judging me or that it will affect my grades. You learn by your mistakes." (Man respondent)

"What made me participate in class was reading up on what we would go through in the lecture ahead of the lecture, so that I had a certain idea of what it would be about." (Man respondent)

"The problem is that too many people have strong opinions... It's also a fact that some students are very smart and read a lot, and this makes other students dread to participate with whatever knowledge they might possess." (Man respondent)

"This is my first course in politics and I started studying with an interest for the course but with no previous knowledge." (Woman respondent)

"Boys have a more powerful and dominant voice and I think it's more natural for them to speak up in big crowds. I never raised my hand during a lecture but would never have a problem answering the question if someone gave me a chance to answer." (Woman respondent)

"Biological differences between the genders. I [participated] and would from time to time disagree with comments from other students that I felt needed to be corrected." (Man respondent) 
Another possibility is that women experience a higher susceptibility to stereotype threat, which inhibits academic performance of individuals who identify within domains where negative-ability stereotypes exist. Previous research demonstrated how this phenomenon affects ethnic minorities (Nguyen and Ryan 2008;
Steele 1997; Steele and Aronson 1995) and women (e.g., within male-stereotyped STEM disciplines) (Cheryan et al. 2009; Spencer, Steele, and Quinn 1999). Fortunately, empirical research demonstrates multiple strategies to combat stereotype threat in the classroom, such as removing cues that endorse or confirm

\section{If the décor sends signals about who belongs in a computer-science learning environment, a semester focused on powerful male leaders in history also may send a strong message to students-even if the instructor does not intend to convey these messages through course content.}

\section{Figure 1}

\section{Gender Gap in Participation in Comparative Politics Course}

A Guest lecturers' classes

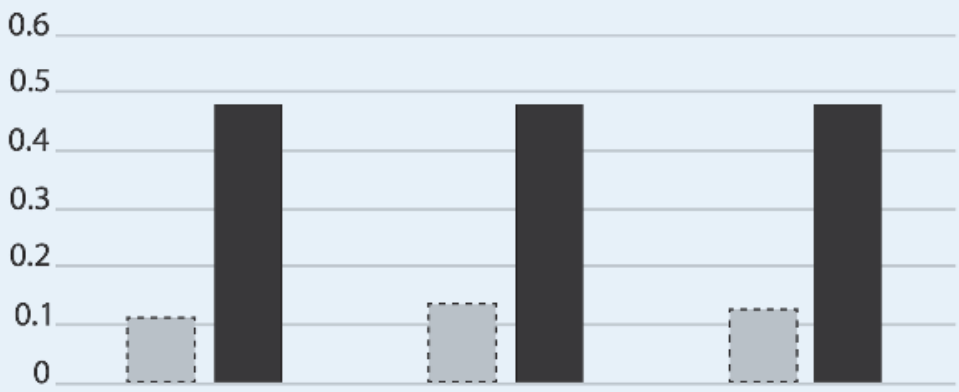

B Primary instructors' classes

0.6

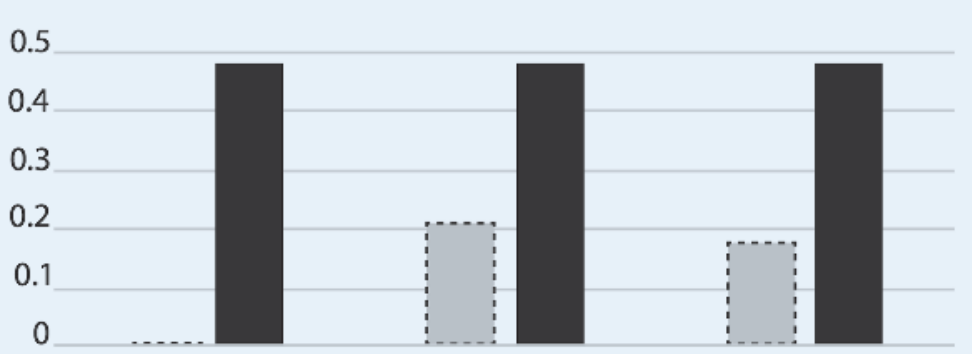

C Combined summary

0.6

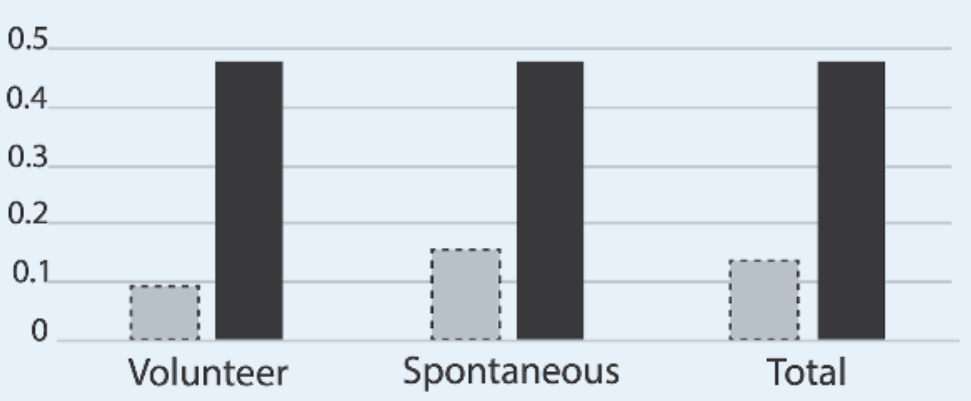

\section{:Observed Expected}

Observed (gray bars dashed lines) versus expected (black bars) proportions of participants who are women in whole-classroom discussions in introductory comparative politics across randomly observed (A) guest lecturers' classes, (B) lead instructors' classes, and $(C)$ a combined summary of all guest-lecturer and lead instructor's classes. Shown are two different types of instructor-student interactions in the classroom, including volunteer and spontaneous responses. All observed proportions of participating students who are women were significantly less than expected given the number of women in the classroom; therefore, all $p<0.05$. stereotypes (Cheryan et al. 2009; Danaher and Crandall 2008; Logel et al. 2009; Steele and Aronson 1995). For example, Cheryan et al. (2009) showed that women lose interest in computer-science classrooms when objects in the room signal that the people there are geeky men (e.g., Star Trek posters and empty soda cans from all-night coding sessions) as opposed to a neutral physical environment. If the décor sends signals about who belongs in a computerscience learning environment, a semester focused on powerful male leaders in history also may send a strong message to students-even if the instructor does not intend to convey these messages through course content.

A clear avenue for future research is to examine the effects of presenting diverse political leaders in a comparative-politics course and to quantify similar output variables (e.g., participation, performance, and intention to stay in the discipline). Other examples of ways to reduce stereotype threat and promote inclusivity include using gender- and culture-fair tests and curriculum materials to ensure that there are no biases against certain groups in academic-performance measurements (Good, Aronson, and Harder 2008; Spencer, Steele, and Quinn 1999; Steele and Aronson 1995); conveying to students that diversity is valued (Purdie-Vaughns et al. 2008); supporting students' sense of 
belonging (Walton and Cohen 2011); engaging students in valueaffirmation activities (Cohen et al. 2009; Martens et al. 2006); and improving intergroup relations (Page-Gould, Mendoza-Denton, and Tropp 2008; Steele 1997). In addition, women may feel marginalized due to lack of exposure to other women as examples featured in lectures. Women are underrepresented globally in politics ("The Global Gender Gap Report" 2016), a phenomenon that may be self-fulfilling: the representation of political power as exclusively male may affect the behavior and performance of women. Therefore, a simple solution may be to create a critical mass by increasing visibility of underrepresented groups in the field (Cotner et al. 2011; Murphy, Steele, and Gross 2007; PurdieVaughns et al. 2008). Women also may be subject to the "double bind" of conflicting expectations. In whole-class discussion, women face limited options-they can choose to be more than, less than, or similarly opinionated and knowledgeable as male students. Acting more opinionated and outspoken counters peer expectations of feminine behavior, resulting in potential social costs of speaking out regularly (Jamieson 1995). Making participation part of the students' grade or using a random number generator to call on students may normalize outspoken behavior and lower the perceived threat of classroom participation (Eddy, Brownell, and Wenderoth 2014). Other simple in-class interventions that benefit underrepresented groups such as women include small-group discussions (Freeman et al. 2014; Haak et al. 2011; Lorenzo, Crouch, and Mazur 2006; Pollock, Hamann, and Wilson 2011) and women-majority group work.

Our assessment presents political science as a discipline with a unique opportunity to apply and monitor evidence-based methodologies to close the classroom gender gap. The striking lack of participation of women is a problem in urgent need of attention. If promising young political scientists do not speak up in the classroom, we cannot expect them to assert their opinions farther along the academic pathway or in a political arena outside of academia. Fostering an inclusive classroom environment that explicitly values diversity will improve access to political science for all students.

\section{SUPPLEMENTARY MATERIAL}

To view supplementary material for this article, please visit https://doi.org/10.1017/S1049096518000045.

\section{ACKNOWLEDGMENTS}

We thank Marie Danielsen for help with data collection and Oddfrid T. Kårstad Førland, Vigdis Vandvik, and Lucas Jeno for additional support. This research was approved by NSD Prosjektnr 46727 and funded by the Centre of Excellence in Biology Education (bioCEED) at the University of Bergen and the Department of Biology Teaching and Learning at the University of Minnesota. Cissy Ballen was supported by a Research Council of Norway Mobility Grant (Proposal No. 261529) awarded to Sehoya Cotner.

\section{NOTE}

1. This is an introductory course with a mandatory short-term paper and a six-hour final exam. Participation in lectures is not mandatory and it is customary for students to repeat the exam in their third semester to improve their grade (but not participate in class). This accounts for approximately 30 of the 130 students that passed the December 2016 final exam.

\section{REFERENCES}

American Political Science Association. 2005. "Women's Advancement in Political Science." Washington, DC.
Anonymous. 1999. "Tenure in a Chilly Climate." PS: Political Science \& Politics 32 (1): 91-9.

Ballen, Cissy J., Marie Danielsen, Christian Jørgensen, John-Arvid Grytnes, and Sehoya Cotner. 2017. "Norway's Gender Gap: Classroom Participation in Undergraduate Introductory Science." Nordic Journal of STEM Education 1 (1): 179-86.

Banks, Taunya Lovell. 1988. "Gender Bias in the Classroom.” Journal of Legal Education 38 (1/2): 137-46.

Bates, Stephen, Laura Jenkins, and Zoe Pflaeger. 2012. "Women in the Profession: The Composition of UK Political Science Departments by Sex." Politics 32 (3): $139-52$.

Bekhouche, Yasmina, Ricardo Hausmann, L. D. Tyson, and Saadia Zahidi. 2013. "The Global Gender Gap Report 2013." Geneva, Switzerland: World Economic Forum.

Betz, Nancy E., and Gail Hackett. 1981. "The Relationship of Career-Related Self-Efficacy Expectations to Perceived Career Options in College Women and Men." Journal of Counseling Psychology 28 (5): 399-410.

Blickenstaff, Jacob Clark. 2005. "Women and Science Careers: Leaky Pipeline or Gender Filter?" Gender and Education 17 (4): 369-86.

Burke, Ronald J., and Mary C. Mattis. 2007. Women and Minorities in Science, Technology, Engineering, and Mathematics: Upping the Numbers. Northhampton, MA: Edward Elgar Publishing.

Ceci, Stephen J., Wendy M. Williams, and Susan M. Barnett. 2009. "Women's Underrepresentation in Science: Sociocultural and Biological Considerations." Psychological Bulletin 135 (2): 218.

Cheryan, Sapna, Victoria C. Plaut, Paul G. Davies, and Claude M. Steele. 2009. "Ambient Belonging: How Stereotypical Cues Impact Gender Participation in Computer Science." Journal of Personality and Social Psychology 97 (6): 1045.

Cohen, Geoffrey L., Julio Garcia, Valerie Purdie-Vaughns, Nancy Apfel, and Patricia Brzustoski. 2009. "Recursive Processes in Self-Affirmation: Intervening to Close the Minority Achievement Gap." Science 324 (5925): 400-403.

Cotner, Sehoya, Cissy Ballen, D. Christopher Brooks, and Randy Moore. 2011. "Instructor Gender and Student Confidence in the Sciences: A Need for More Role Models." Journal of College Science Teaching 40 (5): 96-101.

Danaher, Kelly, and Christian S. Crandall. 20o8. "Stereotype Threat in Applied Settings Reexamined.” Journal of Applied Social Psychology 38 (6): 1639-55.

Eddy, Sarah L., Sara E. Brownell, and Mary Pat Wenderoth. 2014. "Gender Gaps in Achievement and Participation in Multiple Introductory Biology Classrooms." CBE-Life Sciences Education 13 (3): 478-92.

Freeman, Scott, Sarah L. Eddy, Miles McDonough, Michelle K. Smith, Nnadozie Okoroafor, Hannah Jordt, and Mary Pat Wenderoth. 2014 "Active Learning Increases Student Performance in Science, Engineering, and Mathematics." Proceedings of the National Academy of Sciences USA 111 (23): 8410-15.

“The Global Gender Gap Report.” 2016. Geneva, Switzerland: World Economic Forum.

Good, Catherine, Joshua Aronson, and Jayne Ann Harder. 2008. "Problems in the Pipeline: Stereotype Threat and Women's Achievement in High-Level Math Courses." Journal of Applied Developmental Psychology 29 (1): 17-28.

Haak, David C., Janneke Hille Ris Lambers, Emily Pitre, and Scott Freeman. 2011. "Increased Structure and Active Learning Reduce the Achievement Gap in Introductory Biology." Science 332 (6034): 1213-16.

Hesli, Vicki L., and Jae Mook Lee. 2011. "Faculty Research Productivity: Why Do Some of Our Colleagues Publish More Than Others?” PS: Political Science $\mathcal{E}$ Politics 44 (02): 393-408.

Jamieson, Kathleen Hall. 1995. Beyond the Double Bind: Women and Leadership. Oxford: Oxford University Press on Demand.

Logel, Christine, Gregory M. Walton, Steven J. Spencer, Emma C. Iserman, William von Hippel, and Amy E. Bell. 2009. "Interacting with Sexist Men Triggers Social Identity Threat among Female Engineers." Journal of Personality and Social Psychology 96 (6): 1089.

Lorenzo, Mercedes, Catherine H. Crouch, and Eric Mazur. 2006. "Reducing the Gender Gap in the Physics Classroom." American Journal of Physics 74 (2): 118-22.

Martens, Andy, Michael Johns, Jeff Greenberg, and Jeff Schimel. 2006. "Combating Stereotype Threat: The Effect of Self-Affirmation on Women's Intellectual Performance." Journal of Experimental Social Psychology 42 (2): 236-43.

McGlone, Matthew S., Joshua Aronson, and Diane Kobrynowicz. 2006. "Stereotype Threat and the Gender Gap in Political Knowledge." Psychology of Women Quarterly 30 (4): 392-8.

Mitchell, Sara McLaughlin, and Vicki L. Hesli. 2013. "Women Don't Ask? Women Don't Say No? Bargaining and Service in the Political Science Profession." PS: Political Science \& Politics 46 (2): 355-69.

Monroe, Kristen, Saba Ozyurt, Ted Wrigley, and Amy Alexander. 2008. "Gender Equality in Academia: Bad News from the Trenches, and Some Possible Solutions." Perspectives on Politics 6 (2): 215-33. 
Monroe, Kristen Renwick, and William F. Chiu. 2010. "Gender Equality in the Academy: The Pipeline Problem.” PS: Political Science \& Politics 43 (2): 303-308.

Moss-Racusin, Corinne A., John F. Dovidio, Victoria L. Brescoll, Mark J. Graham, and Jo Handelsman. 2012. "Science Faculty's Subtle Gender Biases Favor Male Students." Proceedings of the National Academy of Sciences 109 (41): 16474-9.

Murphy, Mary C., Claude M. Steele, and James J. Gross. 2007. "Signaling Threat: How Situational Cues Affect Women in Math, Science, and Engineering Settings." Psychological Science 18 (10): 879-85.

Nguyen, Hannah-Hanh D., and Ann Marie Ryan. 2008. "Does Stereotype Threat Affect Test Performance of Minorities and Women? A Meta-Analysis of Experimental Evidence." Journal of Applied Psychology 93 (6): 1314.

Ong, Maria, Carol Wright, Lorelle Espinosa, and Gary Orfield. 2011. "Inside the Double Bind: A Synthesis of Empirical Research on Undergraduate and Graduate Women of Color in Science, Technology, Engineering, and Mathematics." Harvard Educational Review 81 (2): 172-209.

Page-Gould, Elizabeth, Rodolfo Mendoza-Denton, and Linda R. Tropp. 2008. "With a Little Help from My Cross-Group Friend: Reducing Anxiety in Intergroup Contexts through Cross-Group Friendship." Journal of Personality and Social Psychology 95 (5): 1080.

Pollock, Phillip H., Kerstin Hamann, and Bruce M. Wilson. 2011. "Learning Through Discussions: Comparing the Benefits of Small-Group and Large-Class Settings." Journal of Political Science Education 7: 48-64.
Purdie-Vaughns, Valerie, Claude M. Steele, Paul G. Davies, Ruth Ditlmann, and Jennifer Randall Crosby. 2008. "Social Identity Contingencies: How Diversity Cues Signal Threat or Safety for African Americans in Mainstream Institutions." Journal of Personality and Social Psychology 94 (4): 615 .

Spencer, Steven J., Claude M. Steele, and Diane M. Quinn. 1999. "Stereotype Threat and Women's Math Performance." Journal of Experimental Social Psychology 35 (1): 4-28.

Steele, Claude M. 1997. "A Threat in the Air: How Stereotypes Shape Intellectual Identity and Performance." American Psychology 52 (6): 613-29.

Steele, Claude M., and Joshua Aronson. 1995. "Stereotype Threat and the Intellectual Test Performance of African Americans.” Journal of Personality and Social Psychology 69 (5): 797-811.

Steele, Jennifer, Jacquelyn B. James, and Rosalind Chait Barnett. 2002. "Learning in a Man's World: Examining the Perceptions of Undergraduate Women in Male-Dominated Academic Areas." Psychology of Women Quarterly 26 (1): 46-50.

Timperley, Claire. 2013. "Women in the Academy: Key Studies on Gender in Political Science." Political Science 65 (1): 84-104.

Walton, Gregory M., and Geoffrey L. Cohen. 2011. "A Brief Social-Belonging Intervention Improves Academic and Health Outcomes of Minority Students." Science 331 (6023): 1447-51. 